EGU21-10190

https://doi.org/10.5194/egusphere-egu21-10190

EGU General Assembly 2021

(c) Author(s) 2021. This work is distributed under

the Creative Commons Attribution 4.0 License.

\title{
Lablab purpureus (L.) Sweet soil-plant system towards the recovery of marginal lands
}

\author{
Patrícia Vidigal ${ }^{1}$, Marino Pedro Reyes-Martín ${ }^{2}$, and Maria Manuela Abreu ${ }^{1}$ \\ ${ }^{1}$ Linking Landscape Environment, Agriculture and Food (LEAF) Research Center, School of Agriculture, University of Lisbon, \\ 1349-017 Lisbon, Portugal \\ ${ }^{2}$ Department of Soil Science and Agricultural Chemistry, University of Granada, Av. de Fuente Nueva s/n, 18071 Granada, \\ Spain
}

Land represents $29 \%$ of the earth surface, and $71 \%$ of which is habitable, but only $50 \%$ is suitable for agricultural, which makes agricultural land a valuable and finite natural resource that has been experiencing increasing pressure to respond to food, feed, industrial and population housing needs. Thus, it is necessary to change the way in which we eat and live. Mismanagement of agricultural inputs together with the improvement of human living standards and urbanization has stimulated the demand and market potential of mining and quarrying market, which has promoted the occurrence of contaminated soils with potentially hazardous elements (PTE). The recovery of marginal lands, such as salt and drought prone lands, or even abandoned mining areas could be a potential strategy to decrease the pressure over the remaining agricultural land, whilst promoting ecosystem biodiversity. The recovery of mining areas, although still controversial, it is not totally dismissible because one has to increase the knowledge of plant species that could aid in the recovery of soil contaminated PTE whilst offering alternative industrial agricultural outputs. There has been increasing efforts to create sustainable ecotechnologies to rehabilitate mining areas and create conditions for agriculture activities while protecting the food-chain. Phytostabilization is an ecotechnology towards rehabilitation, based on pedo-engineering in which Technosols are built from organic/inorganic and mine wastes (e.g. gossan), thus promoting circular economy. The effectiveness of Technosols in improving the physico-chemical characteristics of mining wastes and in the decrease of their leachates has been widely proven, especially when soil-plant systems are taken into account. Our experiment with Technosols and a multifunctional legume hyacinth bean (Lablab purpureus (L.) Sweet) showed just that. Hyacinth bean is one of the 101 orphan crops that recently have been recognized as crops for the future, due to the prospective they hold as food, feed, nutritional content and multiple agricultural outputs. Our Technosols built with organic and inorganic wastes collected from nearby industries, together with gossan material, improved the physico-chemical and biological properties of the gossan, as well as they decreased the bioavailability of PTE (As, Pb, Zn, Cu) in the soil available fraction, making it possible for hyacinth bean to develop. Our Technosols showed increased content in NPK and $\mathrm{C}_{\text {org }}$, which was concurrent with a significant increase of soil enzymes activity, proving soil quality enhancement aiding hyacinth bean development. Moreover, hyacinth bean grown in Technosols showed an impressive shoot and root development in comparison with 
hyacinth bean grown in gossan. The PTE translocation (root to shoot) and accumulation (soil to shoot) coefficients values of this legume grown in Technosols indicated low PTE concentrations in the shoot, which are compatible with the potential of hyacinth bean for the rehabilitation of contaminated soils, whilst offering alternative revenues (e.g. feed). Hence, these results show the value that this orphan crop has when allied with a promising ecotechnology that contributes to promote circular economy, towards the new European Green Deal policy framework. 